Article

\title{
Configuring the Older Non-User: Between Research, Policy and Practice of Digital Exclusion
}

\author{
Vera Gallistl ${ }^{1, *}$, Rebekka Rohner ${ }^{1}$, Alexander Seifert ${ }^{2}$ and Anna Wanka ${ }^{3}$ \\ ${ }^{1}$ Department of Sociology, University of Vienna, 1090 Vienna, Austria; E-Mails: vera.maria.gallistl@univie.ac.at (V.G.), \\ rebekka.rohner@univie.ac.at (R.R.) \\ 2 Institute of Sociology, University of Zurich, 8050 Zurich, Switzerland; E-Mail: alexander.seifert@uzh.ch \\ 3 Institute of Social Pedagogy and Adult Education, Goethe University Frankfurt, 60629 Frankfurt, Germany; \\ E-Mail: wanka@em.uni-frankfurt.de \\ * Corresponding author
}

Submitted: 31 October 2019 | Accepted: 7 February 2020 | Published: 14 May 2020

\begin{abstract}
Older adults face significant barriers when accessing the Internet. What can be done to address these barriers? This article analyses existing strategies to tackle the age-related digital divide on three different levels: research, policy and practice. It analyses (1) scientific conceptualisations that are used when studying Internet use and non-use in later life, (2) policies that address older adults' Internet (non-)use in Austria and (3) characteristics of older Austrian non-users of the Internet based on the Survey of Health, Ageing and Retirement in Europe (SHARE, wave 6). Analysis shows that Austrian policy tends to emphasise the individual responsibility to learn digital technologies, while placing a lower priority on structural issues, such as investments in infrastructure. However, SHARE data shows that only a small percentage of older non-users of the Internet is in fact reached with such interventions. Thus, this article suggests that policy needs to base its strategies on more refined understandings of Internet use and non-use in later life as well as a more nuanced image of the older non-user. A perspective of critical-cultural gerontology, as laid out in this article, highlights that technology adoption is a domestication process that takes place in the everyday lives of older adults, and it is these processes that interventions that tackle the age-related digital divide should take as a starting point.
\end{abstract}

\section{Keywords}

age; ageing; Austria; digital divide; digital exclusion; digital policies

\section{Issue}

This article is part of the issue "Digital Inclusion Across the Globe: What Is Being Done to Tackle Digital Inequities?" edited by Bianca C. Reisdorf (University of North Carolina at Charlotte, USA) and Colin Rhinesmith (Simmons University, USA).

(C) 2020 by the authors; licensee Cogitatio (Lisbon, Portugal). This article is licensed under a Creative Commons Attribution 4.0 International License (CC BY).

\section{Introduction}

Digital technologies, especially information and communication technologies (ICT) such as computers, smartphones or tablets permeate all aspects of our lives (Castells, 2010), older adults notwithstanding. While access to the Internet through these devices has become widespread across the globe, a gap between age groups persists (Hunsaker \& Hargittai, 2018; Seifert \& Rössel, 2019). In 2015, fewer than $10 \%$ of those aged 80 and older in the EU accessed the Internet, while $48 \%$ of
Europeans aged 65-69 did so (König, Seifert, \& Doh, 2018). However, while the first level of the digital divideinequalities in access to the Internet-has been significantly reduced across Europe in the last decade, the second and third level of the age-related digital divideinequalities in competence and performance-are still prevalent (Negreiro, 2015) and are much harder to grasp with political interventions. Digital inclusion, which comprises access, skills, attitudes and different levels of engagement with the Internet (Helsper, 2012), is therefore still unequally distributed across age groups. 
Consequently, research in gerontology has put the question why older adults use or do not use the Internet on its agenda (Schulz et al., 2015). Early on, studies have highlighted the relevance of psychological factors, claiming that older adults are less likely to use the Internet because they show a higher prevalence of computer anxiety (Cattaneo, Malighetti, \& Spinelli, 2016; Charness \& Boot, 2009; Lee, Chen, \& Hewitt, 2011; Neves, Amaro, \& Fonseca, 2013; Silver, 2015), frustration with user interfaces (Damodaran, Olphert, \& Phipps, 2013; Gatto \& Tak, 2008; Hussain, Ross, \& Bednar, 2017), negative attitudes toward technology (Kamin, Lang, \& Beyer, 2017; Reisdorf \& Groselj, 2017), and higher concerns about security issues on the Internet, mainly regarding personal information (Gatto \& Tak, 2008; Hussain et al., 2017; Lee et al., 2011). Second, research has highlighted that older adults face health-related barriers when accessing digital technologies, arguing that access to the Internet is more challenging for those with, e.g., poor eyesight, shaky hands, or (mild) cognitive impairment (Charness \& Boot, 2009; Cresci, Yarandi, \& Morrell, 2010; Damodaran et al., 2013; Gatto \& Tak, 2008; Hussain et al., 2017; Lee et al., 2011; Lelkes, 2013). Third, research has identified multiple socio-economic factors, mainly education and income, as predictors of older adults' Internet use. Low education and income (Charness \& Boot, 2009; Cresci et al., 2010; Lelkes, 2013; Neves \& Amaro, 2012), which impede and complicate access to devices, have been identified as main determinants of Internet use in later life (Bakaev, Ponomarev, \& Prokhorova, 2008; Charness \& Boot, 2009) and some studies even suggest that it is not age itself, but rather a combination of experience and level of education that determines the level of computer anxiety in later life (Fernández-Ardèvol \& Ivan, 2015). This wide variety of influential factors highlights that it might not be age itself, but rather the social positions and resources of older adults that determine Internet use in later life. Further, Internet use in later life might also be a question of technological development and design, as research has noted that products are often poorly designed for older adults and therefore uncomfortable or at times even unmanageable to use (Charness \& Boot, 2009; Czaja, Boot, Charness, \& Rogers, 2019; Damodaran et al., 2013).

While research has identified multiple factors that explain why older adults use or do not use the Internet, interventions that support digital inclusion in later life have received less attention. For a long time, research on such interventions has focussed on online or face-toface training courses as one strategy to support Internet use in later life (for empirical studies, see, e.g., Černá \& Svobodová, 2018; Damodaran et al., 2013; Esteller-Curto \& Escuder-Mollon, 2012; Fernández, Esteban, Conde, \& Rodríguez-Lera, 2016; Kokol \& Stiglic, 2011; Sitti \& Nuntachompoo, 2013; Yamauchi, Yasuda, \& Yokoi, 2008), making individual learning the most common strategy to prevent digital exclusion in older age.

Such individualized accounts of Internet use and nonuse in later life, are, however, increasingly up for ques- tion. One of the more critical approaches towards the topic has been framed as a material praxeology of ageing with technologies (Wanka \& Gallistl, 2018), which assumes that using or not using a certain technology in later life is not a result of an informed decision or an individual learning process, but influenced by variety of agents within a social field-individuals, institutions, discourses and technological devices-and the power relations between those agents. From this perspective, nonuse of the Internet in later life is not an individual process, but "co-constituted in a social field, comprised of actors, discourses and power relations" (Wanka \& Gallistl, 2018, p. 14): The way in which access to the Internet is supported by relatives and friends, the media discourses surrounding age and demographic change, the institutions which enable or restrain older adults' access to educational programs all might be involved in shaping Internet use and non-use in later life. To develop a more nuanced understanding of use and non-use of digital technologies in later life, hence, we need to take more than the older individual into account and instead ask which discourses in policy (and research) shape our understandings of Internet use and how these understandings relate to the everyday lives of older adults.

Taking such a perspective as a starting point, this article critically examines the political interventions that aim to support Internet use of older adults, asking: How is the use and non-use of digital technologies framed by policy? Which aspects of digital inclusion and exclusion are addressed by policies, and which ones are left out? And how do these framings relate to the actual characteristics of older non-users of the Internet? To do so, this article analyses existing strategies to tackle the agerelated digital divide on three different levels. First, it takes a critical look at the concepts used when studying Internet use and non-use in later life, asking which policy implications derive from these concepts. Second, it analyses the three most influential Austrian policy papers on demographic change to explore which interventions are suggested to address the age-related digital divide and which assumptions on older non-users can be found in these papers. Finally, it juxtaposes these assumptions with Austrian data on older non-users of the Internet from the Survey of Health, Ageing and Retirement in Europe (SHARE, 2015) and asks how likely it is that the suggested interventions actually reach older non-users.

\section{Conceptualising the Non-Use of Digital Technologies in Later Life: Critical and Cultural Perspectives}

Which scientific concepts are used when studying Internet use and non-use in later life and which policy implications can be derived from these concepts? In gerontology, rational choice theories are most commonly used to explain Internet use and-more generallytechnology use and non-use among older adults (Kolland, Wanka, \& Gallistl, 2019). However, such approaches have been heavily criticised for reducing human behaviour 
to economic models and underestimating the influence of socio-structural factors in later-life technology use (Künemund \& Tanschus, 2014). In contrast to rational choice models, critical and cultural gerontology have highlighted the interconnection between the ageing experience in its socio-cultural contexts and the embeddedness of technology use in the everyday lives of older adults (see, e.g., Endter, 2016; Marshall \& Katz, 2016; Neven \& Peine, 2017). Internet use and non-use in later life is understood not so much a result of an informed and competent decision by a potential user, but a result of everyday practices, policies and discourses. Critical and cultural gerontology are concerned with this embeddedness in two ambivalent and often contradictory contexts: the everyday lives of older adults and the policy and media discourses surrounding them.

Analysing policy discourses surrounding ageing and technologies, critical scholars have shown how population ageing is often conceptualised as a societal crisis, whereas technological development is framed as its solution. This results in a triple-win rhetoric (Neven \& Peine, 2017) surrounding technology use in later life. First, the care system can reduce costs; second, the economy finds a new market for growth; third, older adults themselves benefiting from technological solutions via a higher quality of life. This discourse, however, also puts older users of these technologies in a problematic position: While ageing is understood as an imminent crisis that must be 'solved' by technology, the non-use of digital technologies becomes a threat to this solution. A critical perspective on Internet use in later life, hence, requires questioning this problematisation and asking when, how, and for whom non-use might be problematic. Therefore, this perspective calls for interventions that "fit in with the lives of older people" (Neven \& Peine, 2017, p. 13) rather than the logics of the ageing-and-innovation discourse.

This concern for poor compatibility between policy discourses and everyday lives of older adults leads directly to the other dimension highlighted by cultural and critical gerontology when conceptualising technology use and non-use in later life, namely its embeddedness in the everyday lives of older adults. Critical and cultural gerontology argues that the "rhythms and patterns that underlie the habitual and routinised everyday worlds" (Pilcher, Martin, \& Williams, 2016, p. 678) of older adults are often overlooked in gerontological research. Hence, interventions need to investigate closely under which circumstances Internet use in later life is perceived as beneficial and under which circumstances it is not (Gallistl \& Nimrod, 2019). Ethnographic studies have, e.g., shown how older adults who use medical alert bracelets consequently frame themselves as frail and vulnerable (Aceros, Pols, \& Domènech, 2015), or highlighted how the incompetent use of the Internet by older adults might disrupt established hierarchies within families, where older men are often seen as techno-savvy grandfathers (Thalhammer \& Schmidt-Hertha, 2015). Hence, interventions that tackle the age-related digital divide should be clearer in why, for what reasons and under which circumstances technologies can be beneficial for which groups of older adults and why technology use should be supported in later life.

As a consequence, a critical and cultural gerontological perspective puts the conceptualisation of non-use of the Internet as problematic into question. It also questions if use and non-use can be understood as binary variables per se. In 'real life,' there is arguably no such thing as a complete or absolute non-user of digital technologies. Instead, non-use is processual and fluid, with usage practices, non-usage practices as well as hybrid practices being constantly interwoven in the everyday lives of older adults (van Deursen \& Helsper, 2015). Internet use and non-use is more complex than presumed by rational choice models, and the same holds true for older nonusers. Studies that identify usage barriers of older adults toward new technologies often assume a homogenous group of older non-users (Reisdorf \& Groselj, 2017) and rational choice models tend to reinforce this homogenisation by rationalising non-use through the lack of potentially positive outcomes and ease of use.

To summarise, the non-use of the Internet in later life is not (only) based on older adults' lack of motivation or skills, their health or social networks, but rather constituted in the complex interplay between policy and media discourses and the everyday lives of a heterogeneous group of older persons. Internet use and nonuse in later life is constituted in complex social fields (Wanka \& Gallistl, 2018) and successful interventions should therefore not only target older individuals themselves but also the policy discourses surrounding them. In the following empirical analysis, we hence raise two research questions:

(1) How is older adults' non-use of the Internet problematised in Austrian policies and which solutions are formulated to tackle the age-related digital divide?

(2) How likely are older non-users of the Internet reached by the interventions outlined in policy papers and which alternative solutions can be suggested?

\section{Methods}

This article aims to juxtapose Austria's policies on demographic change with everyday practices of older nonusers of the Internet. To do so, it follows a mixed-method design that first analyses Austrian policy papers that target demographic change. The presented results are based on a review that was conducted in 2018. In this review, we identified the three most influential policy papers on demographic change in Austria and coded its contents (Table 1).

Second, we conducted an analysis of Austrian SHARE data to explore how likely older (65+ years) non-users of the Internet are to be reached by the interventions 
Table 1. Austrian policy papers used for the analysis.

\begin{tabular}{|c|c|c|}
\hline Publisher & Date & Title \\
\hline Governing Parties ÖVP and FPÖ & 2018-2019 & $\begin{array}{l}\text { Government Program (2017-2022): } \\
\text { "Together for Austria" }\end{array}$ \\
\hline $\begin{array}{l}\text { Federal Ministry of Labour, Social Affairs, Health } \\
\text { and Consumer Protection (BMASGK) }\end{array}$ & 2016 & Guidelines for General Seniors' Development \\
\hline $\begin{array}{l}\text { Federal Ministry of Teaching, Art and Culture (BMUKK), } \\
\text { Federal Ministry of Science and Research (BMWF), } \\
\text { Federal Ministry of Work, Social and Consumer } \\
\text { Protection (BMASK), Federal Ministry of Economics, } \\
\text { Family and Youth (BMWFJ) }\end{array}$ & 2011 & LLL:2020 Strategy for Lifelong Learning \\
\hline
\end{tabular}

outlined in policy papers. Non-use was measured as (1) never having used a computer and (2) not having used the Internet seven days before the survey. SHARE is a cross-national panel database drawn from different European countries, with information on participants aged 50 or older (Börsch-Supan et al., 2013). The present study used data about Austrian respondents aged 65 or older ( $N=2,333$ ) from wave 6 (version 6.1.0; see BörschSupan, 2018), which was collected in 2015.

We employed a binary logistic regression to determine the predictors of being a non-user (not having used the Internet and never having used a computer) using several socio-economic factors-age, gender, income, education, subjective health, activities of daily living, level of urbanisation-as independent variables. Next, a cluster analysis was used to explain the groupspecific heterogeneity of older non-users of the Internet; two-step cluster analysis with log likelihood was used as the distance measure and the Bayesian information criterion as the cluster criterion. Several variables were considered to characterise respondents' everyday-life situations in the cluster analysis, including age, gender, level of education, the ability to make ends meet financially, level of urbanisation, self-perceived health, activities of daily living and leisure activities. The final step evaluated group differences between the four clusters regarding leisure activities and attitudes toward technology-specifically openness, knowledge and interest. The technology-related attitudes were collected in an Austria-specific drop-off questionnaire (SHARE, 2015) that asked questions about openness ("I am open to this"), knowledge ("I don't know about this") and interest ("I'm not interested in this") toward eleven different technical devices, including tablets, smartphones, fitness trackers, auto fall alerts and body fat monitors. If participants were not open toward these technologies, they were designated within the "not open" group, whereas those who were open toward one or more of the eleven devices were designated as belonging to the "open" group. The same procedure was followed for knowledge and interest. Finally, leisure activities (participating in educational courses) were included to explore differences between clusters. Significance was tested us- ing chi-square (leisure activities) and one-way ANOVA (attitudes toward technology).

\section{Results}

4.1. Policy Analysis: How Is Older Adults' Non-Use of the Internet Problematised in Austrian Policies?

Like many European countries, Austria has experienced a demographic transition since the 1960s (Statistic Austria, 2015). However, this was not necessarily mirrored in Austrian policies, which have scarcely dealt with the consequences of demographic change outside of discussions on pensions and care. Given that demographic change is a negligible topic in Austrian policies, policies on Internet use, digital inclusion and demographic change seldomly overlap.

Generally, three major policy papers inform Austria's policies on demographic change, none of them thoroughly addressing the topic of Internet use (Table 1). The most important one is the Austrian government program (2017-2022), which discusses Austria's older population and demographic change under the umbrella topic of pensions, with the clear goal of keeping pensions stable for future generations. Outside of pensions and care, Austria's older population is not mentioned in the program. Topics surrounding Internet use are mostly elaborated on in the government program (under the umbrella term 'digitalisation'), however, not in relation to demographic change. A second key policy paper that informs Austrian policies on demographic change is the Guidelines for General Seniors' Development, which is based on $\$ 19$ of the Federal Seniors Citizens Act. As in all analysed policy papers, quality of life is defined as the most important political goal for the older population in Austria. This general goal should be accomplished through activities described in fourteen different sections (e.g., social and political participation, education and lifelong learning). Internet use of older adults is named as a marginal point within the "Housing Conditions, Technology and Mobility" as well as "Education and Lifelong Learning" sections. Here, the guidelines highlight the most important interven- 
tion to increase the quality of life of older adults, which are learning, education, and guidance services in different areas:

Conducting training courses and digital media courses; conducting language courses, courses in memory training and similar activities; carrying out of activities, specially designed to preserve everyday life skills. (BMASGK, 2016, p. 5)

Therefore, lifelong learning (e.g., through regular courses or training programs) is outlined as the most important intervention to tackle the age-related digital divide. This is mirrored in the third key policy paper that informs policies on demographic change in Austria, LLL:2020 Strategy for Lifelong Learning (henceforth simply called the LLL:2020). The strategy aims to gradually increase retired adults' participation in learning programs during retirement to at least $12 \%$. Several interventions are specifically named to reach this goal, e.g., nation-wide and professional learning and guidance services. However, the LLL:2020 strategy also acknowledges that older adults' access to learning programs is marginal in Austria:

A nationwide program as well as educational counselling for older adults is hardly available. Data on educational participation in retirement is scarce. (BMUKK, BMWF, BMASK, \& BMWFJ, 2011, p. 42)

What main conclusions can be drawn from these policy papers? First, they show that the quality of life in older citizens is the main objective of national policies that target older people. Access to the Internet is mentioned as a topic; however, this is only a secondary goal of policies for older adults in Austria. Because of the strong focus on supporting quality of life, digital inclusion often plays a small role in the analysed policy papers. When Internet use and demographic change are brought together in Austria's policy papers, it is under the umbrella policy of life-long learning, e.g., in the LLL:2020. This policy paper names several strategies for how the use of the Internet in later life can be supported. Education, life-long learn- ing, as well as guidance services are named as the most important interventions. Hence, if the digital inclusion of older adults is mentioned as a topic in Austrian policy papers, individual learning is often named as the only strategy to solve the challenges connected to the digital divide, framing digital inclusion as a problem that can be fixed through individual motivation and learning by older adults themselves-rather than a structural challenge.

\subsection{Analysis of Practice: How Likely Are Older Non-Users of the Internet Reached By The Suggested Interventions?}

Policy analysis showed that learning and training programs are the most common intervention suggested to support Internet use in later life. How likely are older non-users of the Internet reached by these interventions? In the Austrian SHARE sample, 46.1\% ( $n=1,029)$ of the respondents $(65+)$ had neither ever used a computer in their lives nor the Internet in the last seven days, which, for the purpose of this article, lets them fall under the definition of 'non-users.' In line with previous research (Hale, Cotten, Drentea, \& Goldner, 2010; Helsper, 2010; Seifert \& Schelling, 2016; Wangberg et al., 2008), data shows the oldest-old, women, those with lower educational status, those with lower subjective health and those who lived in rural areas were most likely to fall under the definition of non-users of the Internet (see Table 2).

This high percentage (46.1\%) of older non-users of the Internet in Austria calls for a more differentiated view on which types of non-users exist. A twostep cluster analysis using socio-demographic variables, health, and urbanisation levels identified four distinct clusters of older non-users of the Internet: younger nonusers, male non-users, urban non-users, and non-users with health limitations (see Table 3). The first group, "younger non-users," were mainly characterised by their age, which was significantly lower than in the other clusters. Consequently, they were generally in better health. Further, this group was characterized by living in mostly rural environments, with $74 \%$ living in rural areas. The second group was labelled "male non-users," because

Table 2. Binary logistic regression of the predictors of Internet use/non-use.

\begin{tabular}{llr}
\hline Predictors & Odds ratio & Standard error \\
\hline Age & $1.11^{* * *}$ & 0.009 \\
Female & $1.56^{* * *}$ & 0.111 \\
Making ends meet & 0.90 & 0.071 \\
Education (reference: high) & & 0.166 \\
$\quad$ Low & $9.27^{* * *}$ & 0.138 \\
$\quad$ Moderate & $2.45^{* * *}$ & 0.064 \\
Subjective health & $0.81^{* *}$ & 0.180 \\
Activities of daily living & 1.28 & 0.110 \\
Rural area (reference: urban) & $2.23^{* * *}$ & \\
\hline
\end{tabular}

Notes: ${ }^{*} p<0.05 ;{ }^{* *} p<0.01 ;{ }^{* *} p<0.001 ;$ Nagelkerke's $r^{2}=.380 ; x^{2}(8)=680.65, p<.001 ; N=2,037$. Non-use was measured as (1) never having used a computer and (2) not having used the Internet seven days before the survey. 
Table 3. Characteristics of the cluster groups (\%).

\begin{tabular}{|c|c|c|c|c|c|}
\hline \multirow[b]{2}{*}{ Characteristics } & \multicolumn{5}{|c|}{ Non-users } \\
\hline & Younger & Male & Urban & With health limitations & Total \\
\hline Age (mean (SD)) & $70.1(3.35)$ & $76.5(7.11)$ & $76.9(6.78)$ & $81.7(5.88)$ & $76.8(7.30)$ \\
\hline \multicolumn{6}{|l|}{ Gender } \\
\hline Male & 9.5 & 100.0 & 24.0 & 4.2 & 33.7 \\
\hline Female & 90.5 & $\mathrm{n} / \mathrm{a}$ & 76.0 & 95.8 & 66.3 \\
\hline \multicolumn{6}{|l|}{ Education } \\
\hline Low (0-2) & 69.0 & 29.4 & 12.5 & 75.0 & 48.3 \\
\hline Moderate (3-4) & 24.5 & 56.3 & 64.4 & 20.1 & 40.0 \\
\hline High (5-6) & 6.5 & 14.3 & 23.1 & 4.9 & 11.7 \\
\hline \multicolumn{6}{|l|}{ Make ends meet } \\
\hline With difficulty & 22.0 & 11.3 & 12.5 & 24.7 & 18.0 \\
\hline Fairly easily & 26.0 & 30.7 & 33.7 & 35.4 & 31.8 \\
\hline Easily & 52.0 & 58.0 & 53.8 & 39.9 & 50.2 \\
\hline \multicolumn{6}{|l|}{ Subjective health } \\
\hline Very good & 27.0 & 16.0 & 28.4 & 3.1 & 17.2 \\
\hline Good & 36.0 & 21.6 & 57.7 & 22.9 & 33.2 \\
\hline Fair/poor & 37.0 & 62.3 & 13.9 & 74.0 & 49.6 \\
\hline \multicolumn{6}{|l|}{ Activities of daily living } \\
\hline No limitation & 97.5 & 80.1 & 99.5 & 51.4 & 79.3 \\
\hline At least one limitation & 2.5 & 19.9 & 0.5 & 48.6 & 20.7 \\
\hline \multicolumn{6}{|l|}{ Place of Residence } \\
\hline Large cities and suburbs & 13.0 & 14.7 & 72.6 & 20.1 & 29.0 \\
\hline Small towns & 12.5 & 8.2 & 26.4 & 9.0 & 13.5 \\
\hline Rural areas & 74.5 & 77.1 & 1.0 & 70.8 & 57.5 \\
\hline Total (\%) & 21.6 & 24.9 & 22.4 & 31.1 & 100 \\
\hline
\end{tabular}

they consisted solely of males, of whom $77 \%$ lived in rural areas. In contrast to the first group, they reported more health limitations. Notably, this was also the group that reported the highest financial resources, with $58 \%$ of this group reporting they could easily make ends meet financially. The third group was labelled as "urban non-users" because they had the highest percentage of adults living in urban environments of all clusters. This group also reported the highest socio-economic resources, with $23 \%$ reporting a high level of education. Consequently, they also reported high subjective health and only few health limitations. Finally, the last group was labelled as "nonusers with health limitations," a group which consisted almost exclusively (96\%) of women. This group was also the oldest in the sample of non-users and had the highest level of health limitations. They also had the lowest levels of education and had more difficulties making ends meet than persons in the other three clusters.

How likely is it that these diverse clusters of older non-users of the Internet are reached by the policy interventions outlined above? As Table 4 shows, it is mostly younger as well as urban non-users that are reached by educational courses, with five to $6 \%$ of the groups being active in educational programs in the 12 months preceding the survey. In contrast, male non-users and nonusers with health limitations are less active in this context. Table 4 also shows that urban non-users were open to technology and had knowledge of devices but were not interested in using them; indicating a conscious decision to not use the Internet. Conversely, male non-users

Table 4. Group-specific activities and attitudes toward technology (\%).

\begin{tabular}{|c|c|c|c|c|c|}
\hline \multirow[b]{2}{*}{ Characteristics } & \multirow[t]{2}{*}{ Users } & \multicolumn{4}{|c|}{ Non-users } \\
\hline & & Younger & Male & Urban & With health limitations \\
\hline \multicolumn{6}{|l|}{ Leisure activities } \\
\hline Educational courses* & 12.3 & 4.6 & 1.5 & 6.0 & 0.8 \\
\hline \multicolumn{6}{|c|}{ Attitudes toward technology } \\
\hline Openness* & 79.6 & 64.1 & 49.3 & 67.9 & 58.5 \\
\hline No knowledge* & 25.8 & 39.6 & 37.1 & 27.8 & 52.2 \\
\hline No interest* & 80.6 & 75.0 & 76.1 & 87.7 & 66.2 \\
\hline
\end{tabular}

Notes: ${ }^{*} p<0.001$. Significance was tested using chi-square (leisure activities) and one-way ANOVA (attitudes toward technology). 
and non-users with health limitations were less open toward technology. Compared to all other groups, male non-users were the least open toward technology, even though they had a similar knowledge of technologies as younger non-users. Non-users with health limitations had the least knowledge about diverse technical devices. However, non-users with health limitations had the highest interest.

\section{Conclusion}

This article analyses existing strategies to tackle the agerelated digital divide on three different levels: research, policy, and practice. Even though the data is inevitably restricted to the national context of Austria, it highlights three major results.

First, SHARE data analysis showed that older nonusers of the Internet are far from being a homogenous group. Almost half of all respondents (46\%) over the age of 65 reported never having used a computer and not using the Internet. Therefore, interventions to support Internet use in later life need to take the heterogeneity of older non-users of the Internet into account. The study identified four different clusters of older non-users of the Internet: younger non-users, male non-users, urban non-users and non-users with health limitations. Also, regression analysis showed that level of education, level of urbanization and gender were stronger determinants of Internet use than age and health. This result strengthens literature suggesting that the age-related digital divide is not determined by age, but rather low education and level of experience with digital technologies (Fernández-Ardèvol \& Ivan, 2015). Given that age was not the determining variable in our regression models it might therefore be possible that our clusters solution might also be applicable for younger adults. Future research should examine this relationship between diverse clusters of non-users of the Internet more closely to understand if clusters of non-users are specific for the older age-group or not.

Second, analysis showed that while learning and educational programs might be one successful strategy to support older adults' Internet use, these interventions are likely to reach only a small percentage of older nonusers. While younger and urban non-users were likely to be reached by educational programs, non-users with health limitations and male non-users showed hardly any participation in learning activities. This finding strengthens research that explores the selectivity in later-life learning (see, e.g., Gallistl, Wanka, \& Kolland, 2018): Those who have benefited from education and learning over their entire life course are more likely to participate in learning programs later in life. Existing interventions that try to tackle the age-related digital divide therefore run the risk of reaching only those already in a more privileged position and leaving those older adults with the lowest resources behind. Hence, these findings add to literature suggesting that current interventions to sup- port Internet use in later life tend to marginalise the realities of older adults that are less-well off (Sawchuk \& Lafontaine, 2015) and calls for more diversity in strategies to support Internet use in later life.

Third, SHARE data showed that older non-users of the Internet are not only diverse in their socio-economic status, but also in their attitudes and openness toward new technologies in general. Male non-users of the Internet reported significantly less openness toward new technologies. This result is in line with other studies that highlight how technology use in later life is a gendered experience (Helsper, 2010; Pelizäus-Hoffmeister, 2013) and how older males in particular might feel personally threatened by the non-use of digital technologies, as it might disrupts existing hierarchies within families (Thalhammer \& Schmidt-Hertha, 2015). It might also suggest that non-use of the Internet in later life is not only a result of certain barriers that restrict access, but also an expression of a specific taste orientation (Bourdieu, 1979/2013) or attitudes in later life.

Fourth, however, policies on demographic change in Austria seldomly take the outlined heterogeneity of older non-users of the Internet into account. In the analysed policy papers, supporting the Internet use of older adults remains a marginal topic and life-long learning is outlined as the most important one-size-fits-all solution. The older non-user, consequently, is framed as an agentic older adult that can be reached by educational programs. This is somewhat problematic as our study shows that only a very small percentage of older adults can actually be reached by life-long learning. Policies therefore tend to focus on low education as a barrier toward the Internet, while putting other issues (e.g., problematic discourses that marginalise the older population or issues around mobility) into the background. This contributes to the notion that the problem lies at an individual level, while overlooking other factors such as technology design for older adults (Neven \& Peine, 2017).

Which conclusions can be drawn from these results? First, results show that research needs a more complex understanding of Internet (non-)use in later life than what contemporary theories in the field usually offer: Using or not using a certain technology in later life is not a result of an individual and informed decision, but interwoven with policy discourses and institutions surrounding demographic and technological change, as well as the everyday-lives of older adults. A perspective of criticalcultural gerontology, as laid out in this article, points to the fact that technology use and non-use is not a binary variable, but that technology adoption is a domestication process (Silverstone, Hirsch, \& Morley, 1999) which describes the ways in which technologies become incorporated into the everyday lives of users through manifold, ambivalent and often contradictory social processes.

Accordingly, this article highlights the need to design interventions and support strategies to ease older adults' access to the Internet that "fit in with the lives of older people" (Neven \& Peine, 2017, p. 13) rather than 
the assumptions of research and policy. Such more complex understandings of Internet use in later life are, however, missing in Austria's policies on the topic. Hence, our results suggest that policy needs to base its strategies on more refined understandings of technology nonuse in later life as well as a more nuanced image of the older non-user in general. Using or not using the Internet in later life is shaped by a variety of variables, including socio-economic status and individual motivation, but also experience with learning over the life course and older adults' diverse taste orientations, attitudes and interests. It is exactly these processes of domestication, and its surrounding discourses in policy and technological development that interventions used to address the age-related digital divide must take as a point of departure (Sawchuk \& Lafontaine, 2015).

Which alternative interventions need to be thought of to support Internet use in later life? Applying these findings to the development of interventions suggests designing diverse interventions for diverse older target groups. One important division might lie between those who cannot and those who do not want to use digital technologies in later life, which might also call for different approaches when trying to reach these target groups. It also suggests that gerontology should not only put the non-use of digital technologies on its research agenda, but also technology reluctance, resistance, neglect, or taste and that policies should take these constructs more closely into account when designing interventions.

\section{Acknowledgments}

We want to thank the Department of Sociology at the University of Vienna for supporting this article. Within the project MYBL-Supporting Digital Literacy and Appropriation of ICT by Older People (ACCESS), this work was funded by the Austrian Federal Ministry of Education, Science and Research (BMBWF) as part of the MissionERA program (861953). JPI MYBL is supported by J-Age II, which is funded by Horizon 2020, under grant agreement no. 643850.

\section{Conflict of Interests}

The authors declare no conflict of interests.

\section{References}

Aceros, J. C., Pols, J., \& Domènech, M. (2015). Where is grandma? Home telecare, good aging and the domestication of later life. Technological Forecasting and Social Change, 93, 102-111. https://doi.org/10.1016/ j.techfore.2014.01.016

Bakaev, M., Ponomarev, V., \& Prokhorova, L. (2008). E-learning and older people: Barriers and benefits. In Proceedings of the IEEE Region 8 International Conference on Computational Technologies in Electrical and Electronics Engineering (pp. 110-113). Novosi- birsk: Novosibirsk Scientific Centre. https://doi.org/ 10.1109/sibircon.2008.4602586

Börsch-Supan, A. (2018). Survey of health, ageing and retirement in europe (SHARE), wave 6. Share Project. Retrieved from https://doi.org/10.6103/SHARE.w6. 610

Börsch-Supan, A., Brandt, M., Hunkler, C., Kneip, T., Korbmacher, J., Malter, F., . . . Zuber, S. (2013). Data resource profile: The survey of health, ageing and retirement in Europe (SHARE). International Journal of Epidemiology, 42(4), 992-1001. https://doi.org/ 10.1093/ije/dyt088

Bourdieu, P. (2013). Distinction: A social critique of the judgement of taste. London: Routledge. (Original work published 1979)

Castells, M. (2010). The rise of the network society. Malden, MA: Wiley-Blackwell.

Cattaneo, M., Malighetti, P., \& Spinelli, D. (2016). The impact of university of the third age courses on ICT adoption. Computers in Human Behavior, 63, 613-619. https://doi.org/10.1016/j.chb.2016.05.087

Černá, M., \& Svobodová, L. (2018). Development of computer competence courses in seniors: Shift from learning space with computer-based activities to virtual platform-Case study. In S. K. S. Cheung, L.-f. Kwok K. Kubota, L.-K. Lee, J. Tokito (Eds.), Blended learning. Enhancing learning success (pp. 416-425). Berlin: Springer. https://doi.org/10.1007/978-3-31994505-7_34

Charness, N., \& Boot, W. R. (2009). Aging and information technology use: Potential and barriers. Current Directions in Psychological Science, 18(5), 253-258. https://doi.org/10.1111/j.1467-8721.2009.01647.x

Cresci, M. K., Yarandi, H. N., \& Morrell, R. W. (2010). Pro-nets versus no-nets: Differences in urban older adults' predilections for internet use. Educational Gerontology, 36(6), 500-520. https://doi.org/ 10.1080/03601270903212476

Czaja, S. J., Boot, W. R., Charness, N., \& Rogers, W. A. (2019). Designing for older adults: Principles and creative human factors approaches. Boca Raton, FL: CRC Press.

Damodaran, L., Olphert, W., \& Phipps, S. (2013). Keeping silver surfers on the crest of a wave: Older people's ICT learning and support needs. Working with Older People, 17(1), 32-36. https://doi.org/10.1108/ 13663661311312566

Endter, C. (2016). Skripting age. The negotiation of age and aging in ambient assisted living. Ageing and technology: Perspectives from the social sciences. Bielefeld: Transcript.

Esteller-Curto, R., \& Escuder-Mollon, P. (2012). Nonpractical ICT courses for seniors for a comprehensive involvement to provide a global understanding of the Knowledge Society. Procedia-Social and Behavioral Sciences, 46, 2356-2361. https://doi.org/10.1016/ j.sbspro.2012.05.484

Federal Ministry of Labour, Social Affairs, Health 
and Consumer Protection. (2016). Guidelines for general seniors' development. Vienna: BMASGK. Retrieved from https://www.sozialministerium.at/ dam/jcr:3e348609-618e-445c-a922-36f1a67c60ce/ richtlinie_allgemeine_seniorenfoerderung_(ab_1. _8._2016).pdf

Federal Ministry of Teaching, Art and Culture, Federal Ministry of Science and Research, Federal Ministry of Work, Social and Consumer Protection, Federal Ministry of Economics, Family and Youth. (2011). LLL:2020 Strategie zum lebensbegleitenden Lernen in Österreich [LLL:2020 strategy for lifelong learning]. Vienna: Republic of Austria. Retrieved from https://broschuerenservice.sozialministerium. at/Home/Download?publicationld=159

Fernández-Ardèvol, M., \& Ivan, L. (2015). Why age is not that important? An ageing perspective on computer anxiety. In J. Zhou \& G. Salvendy (Eds.), Proceedings of human aspects of IT for the aged population-Design for aging: 1st International Conference on Human Aspects of IT for the Aged Population (pp. 189-200). Cham: Springer International Publishing.

Fernández, C., Esteban, G., Conde, M. Á., \& RodríguezLera, F. J. (2016). ICT for older people to learn about ICT: Application and evaluation. In P. Zaphiris \& A. loannou (Eds.), Lecture notes in computer science (pp. 292-302). Cham: Springer. https://doi.org/10.1007/ 978-3-319-39483-1_27

Gallistl, V., \& Nimrod, G. (2019). Online leisure and wellbeing in later life. In S. Sayago (Ed.), Perspectives on human-computer interaction research with older people (pp. 139-154). Cham: Springer.

Gallistl, V., Wanka, A., \& Kolland, F. (2018). Bildungsbarrieren im Lebenslauf-Effekte kumulativer Bildungsbenachteiligung? [Barriers towards learning over the life course: Cumulative disadvantage?] In R. Schramek, C. Kricheldorff, B. Schmidt-Hertha, \& J. Steinfort-Diedenhofen (Eds.)., Alter(n)-LernenBildung. Ein Handbuch [Handbook of ageing, learning and education]. Stuttgart: Kohlhammer.

Gatto, S. L., \& Tak, S. H. (2008). Computer, internet, and e-mail use among older adults: Benefits and barriers. Educational Gerontology, 34(9), 800-811. https:// doi.org/10.1080/03601270802243697

Hale, T. M., Cotten, S. R., Drentea, P., \& Goldner, M. (2010). Rural-urban differences in general and health-related internet use. American Behavioral Scientist, 53(9), 1304-1325. https://doi.org/10.1177/ 0002764210361685

Helsper, E. J. (2010). Gendered internet use across generations and life stages. Communication Research, 37(3), 352-374. https://doi.org/10.1177/ 0093650209356439

Helsper, E. J. (2012). A corresponding fields model for the links between social and digital exclusion. Communication Theory, 22(4), 403-426.

Hunsaker, A., \& Hargittai, E. (2018). A review of Internet use among older adults. New Media \& So- ciety, 20(10), 3937-3954. https://doi.org/10.1177/ 1461444818787348

Hussain, D., Ross, P., \& Bednar, P. (2017). The perception of the benefits and drawbacks of Internet usage by the elderly people. In C. Rossignoli, F. Virili, \& S. Za (Eds.), Digital technology and organizational change (pp. 199-212). Cham: Springer. https://doi. org/10.1007/978-3-319-62051-0_17

Kamin, S. T., Lang, F. R., \& Beyer, A. (2017). Subjective technology adaptivity predicts technology use in old age. Gerontology, 63(4), 385-392. https://doi.org/ 10.1159/000471802

Kokol, P., \& Stiglic, G. (2011). PRIMER ICT: A new blended learning paradigm for teaching ICT skills to older people. In Proceedings of the 24th International Symposium on Computer-Based Medical Systems (pp. 1-5). Bristol: IEEE. https://doi.org/ 10.1109/cbms.2011.5999119

Kolland, F., Wanka, A., \& Gallistl, V. (2019). Technik und Alter-Digitalisierung und die Ko-Konstitution von Alter(n) und Technologien [Technology and age: Digitalisation and the co-constitution of aging and technologies]. In K. R. Schroeter, C. Vogel, \& H. Künemund (Eds.), Handbuch Soziologie des Alter(n)s [Handbook of the sociology of age and aging] (pp. 1-19). Wiesbaden: Springer.

König, R., Seifert, A., \& Doh, M. (2018). Internet use among older Europeans: An analysis based on SHARE data. Universal Access in the Information Society, 17(3), 621-633. https://doi.org/10.1007/ s10209-018-0609-5

Künemund, H., \& Tanschus, N. M. (2014). The technology acceptance puzzle. Results of a representative survey in Lower Saxony. Zeitschrift für Gerontologie und Geriatrie, 47(8), 641-647. https://doi.org/10.1007/ s00391-014-0830-7

Lee, B., Chen, Y., \& Hewitt, L. (2011). Age differences in constraints encountered by seniors in their use of computers and the internet. Computers in Human Behavior, 27(3), 1231-1237. https://doi.org/10.1016/ j.chb.2011.01.003

Lelkes, O. (2013). Happier and less isolated: Internet use in old age. Journal of Poverty and Social Justice, 21(1), 33-46. https://doi.org/10.1332/175982713×664047

Marshall, B. L., \& Katz, S. (2016). How old am I? Digital culture and quantified ageing. Digital Culture \& Society, 2(1), 145-159. https://doi.org/10.14361/dcs2016-0110

Negreiro, M. (2015). Bridging the digital divide in the EU [Briefing]. Brussels: European Parliamentary Research Service. Retrieved from http://www.europarl. europa.eu/RegData/etudes/BRIE/2015/573884/ EPRS_BRI(2015)573884_EN.pdf

Neven, L., \& Peine, A. (2017). From triple win to triple sin: How a problematic future discourse is shaping the way people age with technology. Societies, 7(26), 1-11. https://doi.org/10.3390/soc7030026

Neves, B. B., \& Amaro, F. (2012). Too old for technology? 
How the elderly of Lisbon use and perceive ICT. The Journal of Community Informatics, 8(1), 1-12.

Neves, B. B., Amaro, F., \& Fonseca, J. R. (2013). Coming of (old) age in the digital age: ICT usage and nonusage among older adults. Sociological Research Online, 18(2), 1-14. https://doi.org/10.5153/sro.2998

Pelizäus-Hoffmeister, H. (2013). Zur Bedeutung von Technik im Alltag Älterer. Theorie und Empirie aus soziologischer Perspektive [The importance of technology in the everyday life of older people. Theory and data from a sociological perspective]. Wiesbaden: Springer.

Pilcher, K., Martin, W., \& Williams, V. (2016). Issues of collaboration, representation, meaning and emotions: Utilising participant-led visual diaries to capture the everyday lives of people in mid to later life. International Journal of Social Research Methodology, 19(6), 677-692.

Reisdorf, B. C., \& Groselj, D. (2017). Internet (non-)use types and motivational access: Implications for digital inequalities research. New Media \& Society, 19(8), 1157-1176. https://doi.org/10.1177/ 1461444815621539

Sawchuk, K., \& Lafontaine, C. (2015). Precarious ageing: Questioning access, creating InterACTion. In P. Dias da Silva \& A. Alves (Eds.), TEM 2015: Proceedings of the technology \& emerging media track: Annual Conference of the Canadian Communication Association (pp. 1-14). Ottawa: Canadian Communication Association. Retrieved from https://acc-cca.ca/wpcontent/uploads/2018/11/SAWCHUK_TEM2015.pdf

Schulz, R., Wahl, H.-W., Matthews, J. T., de Vito Dabbs, A., Beach, S. R., \& Czaja, S. J. (2015). Advancing the aging and technology agenda in gerontology. The Gerontologist, 55(5), 724-734. https://doi.org/ 10.1093/geront/gnu071

Seifert, A., \& Rössel, J. (2019). Digital participation. In D. Gu \& M. E. Dupre (Eds.), Encyclopedia of gerontology and population aging. Chur: Springer International Publishing. https://doi.org/10.1007/978-3319-69892-2_1017-1

Seifert, A., \& Schelling, H. R. (2016). Alt Und Offline? Befunde Zur Nutzung Des Internets Durch Menschen Ab 65 Jahren in Der Schweiz [Old and offline? Findings on the use of the Internet by people aged 65 years and older in Switzerland]. Zeitschrift für Gerontologie und Geriatrie, 49(7), 619-625. https://doi.org/ 10.1007/s00391-015-0965-1

SHARE. (2015). Drop-off questionnaire-Austria (wave 6). Share Project. Retrieved from http://www. share-project.org/fileadmin/pdf_questionnaire_ wave_6/AT_EN_drop-off_w6.pdf

Silver, M. P. (2015). Patient perspectives on online health information and communication with doctors: A qualitative study of patients 50 years old and over. Journal of Medical Internet Research, 17(1). https://doi. org/10.2196/jmir.3588

Silverstone, R., Hirsch, E., \& Morley, D. (1999). Information and communication technologies and the moral economy of the household. In R. Silverstone \& E. Hirsch (Eds.), Consuming technologies: Media and information in domestic spaces (pp. 15-31). London: Routledge.

Sitti, S., \& Nuntachompoo, S. (2013). Attitudes towards the use of ICT training curriculum for Thai elderly people. Procedia-Social and Behavioral Sciences, 103, 161-164. https://doi.org/10.1016/j.sbspro.2013.10. 321

Statistic Austria. (2015). Statistik des Bevölkerungsstandes, Bevölkerungsprognose 2014 [Statistics on population, population forecast 2014]. Statistic Austria. Retrieved from https://statistik.at/wcm/idc/ ichplg?IdcService=GET_PDF_FILE\&RevisionSelection Method $=$ LatestReleased\&dDocName $=043902$

Thalhammer, V., \& Schmidt-Hertha, B. (2015). Intergenerationelle innerfamiliäre Unterstützungsprozesse bei der Mediennutzung von älteren Erwachsenen [Intergenerational familial support for media use by older adults]. Zeitschrift für Erziehungswissenschaft, 18(4), 827-844. https://doi.org/10.1007/ s11618-015-0633-7

van Deursen, A. J., \& Helsper, E. J. (2015). A nuanced understanding of Internet use and non-use among the elderly. European Journal of Communication, 30(2), 171-187. https://doi.org/10.1177/ 0267323115578059

Wangberg, S. C., Andreassen, H. K., Prokosch, H., Santana, S. M., Sørensen, T., \& Chronaki, C. E. (2008). Relations between Internet use, socio-economic status (SES), social support and subjective health. Health Promotion International, 23(1), 70-77. https://doi.org/10. 1093/heapro/dam039

Wanka, A., \& Gallistl, V. (2018). Doing age in a digitized world: A material praxeology of aging with technology. Frontiers in Sociology, 3(6), 1-16.

Yamauchi, A., Yasuda, T., \& Yokoi, S. (2008). Proposal and pilot study of introductory learning course in personal computers for Japanese senior citizens. Journal of Diversity Management, 3(4), 11-18. https:// doi.org/10.19030/jdm.v3i4.4997

\section{About the Authors}

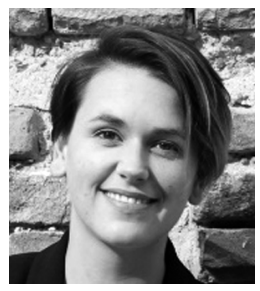

Vera Gallistl is a PhD Candidate and Research Assistant at the Department of Sociology, University of Vienna. Her research interests lie in the field of social gerontology, where she specialized in cultural participation, lifelong learning and the digitalization of later life, which she explores form a criticalcultural gerontological perspective. Methodologically she is specialized in mixed-methods research designs and quantitative multivariate data analysis. 

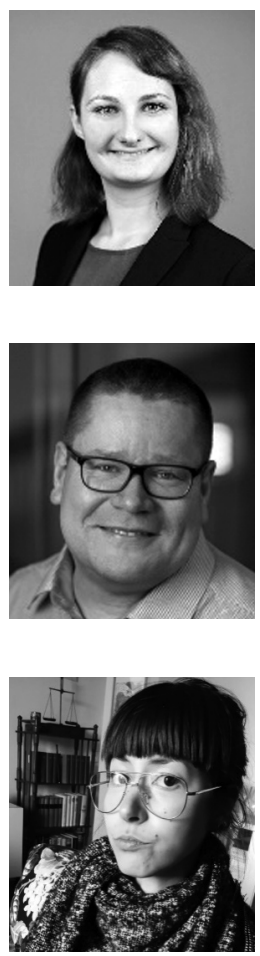

Rebekka Rohner (BA MA) is currently working as a Research Assistant at the University of Vienna. In her research she focuses on ageing and life course, housing in old age, and gerontotechnology. She is well-versed in quantitative and qualitative methods, as well as mixed-methods-approaches.

Alexander Seifert (PhD in Sociology) is Postdoc at the University of Zurich and University of Fribourg. $\mathrm{He}$ is also division manager of the Research Department at the Centre of Competence for Gerontology at the University of Zurich. His research interests include social science approaches to the topics of age(aging), housing, technology/digitization and lifestyles.

Anna Wanka holds a PhD in Sociology from Goethe University Frankfurt am Main, where she is currently working as a Postdoctoral Researcher. Her research interests comprise life course transitions and retirement, ageing and technology, critical and cultural gerontology, 'doing' approaches and practice theories, as well as mixed-methods research. 